University of Nebraska - Lincoln

DigitalCommons@University of Nebraska - Lincoln

2017

\title{
Celebrating 40 Years of the Midwest Nursing Research Society
}

Patricia E. Hershberger

Christine A. Wynd

Laurie K. Glass

Karen M. O'Connell

Joyce J. Fitzpatrick

See next page for additional authors

Follow this and additional works at: https://digitalcommons.unl.edu/usafresearch

This Article is brought to you for free and open access by the U.S. Department of Defense at

DigitalCommons@University of Nebraska - Lincoln. It has been accepted for inclusion in U.S. Air Force Research by an authorized administrator of DigitalCommons@University of Nebraska - Lincoln. 


\section{Authors}

Patricia E. Hershberger, Christine A. Wynd, Laurie K. Glass, Karen M. O'Connell, Joyce J. Fitzpatrick, Nancy Bergstrom, and Sally Lechlitner Lusk 


\title{
Celebrating 40 Years of the Midwest Nursing Research Society
}

Western Journal of Nursing Research 2017, Vol. 39(5) 609-62।

(C) The Author(s) 2017

Reprints and permissions:

sagepub.com/journalsPermissions.nav DOI: $10.1177 / 0193945916688880$ journals.sagepub.com/home/wjn

(S)AGE

\author{
Patricia E. Hershberger', Christine A. Wynd', \\ Laurie K. Glass ${ }^{3}$, Karen M. O'Connell ${ }^{4}$, \\ Joyce J. Fitzpatrick ${ }^{5}$, Nancy Bergstrom ${ }^{6,7}$, \\ and Sally Lechlitner Lusk ${ }^{8}$
}

\begin{abstract}
The Midwest Nursing Research Society (MNRS) recently held its 40th annual conference and celebrated four decades of nursing research in the Midwest. MNRS continues to be one of the largest nursing research societies in the United States. Over the years, a vast majority of programmatic initiatives included education and tangible support for novice and experienced nurse researchers. In this article, the background for development of MNRS is reviewed with examination of driving forces that led to its creation. Three past presidents, Dr. Joyce Fitzpatrick, the first President of MNRS (19801981); Dr. Nancy Bergstrom, the eighth President (1993-1995); and Dr. Sally Lusk, the 14th President (2005-2007), discuss challenges, opportunities, and the exceptional progress made toward fostering excellence in nursing research for the Midwest and contributing to nursing science on a national
\end{abstract}

\footnotetext{
'University of Illinois at Chicago, IL, USA

2Mount Carmel College of Nursing, Columbus, OH, USA

${ }^{3}$ University of Wisconsin-Milwaukee, Milwaukee, WI, USA

${ }^{4}$ Wright Patterson Medical Center, Wright-Patterson Air Force Base, OH, USA

${ }^{5}$ Case Western Reserve University, Cleveland, OH, USA

6UTHealth-Houston (Retired), Houston, TX, USA

7University of Nebraska Medical Center, Omaha, NE, USA

${ }^{8}$ University of Michigan, Ann Arbor, MI, USA
}

\section{Corresponding Author:}

Patricia E. Hershberger, College of Nursing, University of Illinois at Chicago, 845 S. Damen Avenue, Chicago, IL 606I2, USA.

Email: phersh@uic.edu 
and global scale. Lessons from the past as well as opportunities for the future are addressed.

\section{Keywords}

nursing education, nurses as subjects, nursing history, nursing research, nursing science, organizational development

The Midwest Nursing Research Society (MNRS) is one of the largest of nursing research societies in the Nation. For more than 40 years, the mentoring, networking, resource development, and collaboration that are central to this Society have significantly influenced nursing research on a national scale and are becoming increasingly highly regarded on a global level. The purpose of this article is to review major events from the 40-year history of MNRS, identify driving forces behind its development, examine challenges and opportunities for the establishment of the Society, and recognize contributions to national nursing research. The article concludes with a discussion of proposed future directions that will continue to enhance growth of the Society and contributions to the nursing science.

\section{Historical Background and Driving Forces for the Development of MNRS}

The need for nursing-focused doctoral education was identified during the early 1960s, and several federally funded nurse scientist programs provided opportunities for nurses to receive doctoral degrees in other fields (e.g., education, physiology). These programs served to establish qualified nurse scientists to build the science and discipline of nursing. In the Midwest, these programs were located at Case Western Reserve University, the University of Kansas, and the University of Illinois (Minckley, 1980). In the early 1970s, Deans from the Midwest's "Big Ten" universities, as part of the Committee on Institutional Cooperation, began to meet on a regular basis to discuss shared issues and concerns for expanding graduate nursing education, particularly doctoral education, and nursing research. Of note, there was only one doctoral program in nursing, a $\mathrm{PhD}$ program, which opened in 1972 at Case Western Reserve University. Three other doctoral programs in nursing, all $\mathrm{PhD}$ programs, opened in 1975: University of Illinois at Chicago, University of Michigan, and Wayne State University. As a result of the deans' efforts, the Midwest Alliance in Nursing (MAIN) was formed to promote a 
regional system for advancing nursing education for improved nursing practice and rigorous nursing research (McElmurry, 1981; Minckley, 1980).

During the same time frame of the 1970s, a grant from the U.S. Department of Health and Human Services Division of Nursing provided 3 years of support for doctorally prepared nurse faculty to focus research efforts through shared resources. The grant, known as the Nurse Faculty Research Development in the Midwest, supported peer research interest groups (RIGs) to interact and work on shared investigations. Consultations were provided to facilitate the development and implementation of collaborative research and to establish forums for dissemination of research findings (McElmurry \& Minckley, 1986). RIGs became the main structure for these groups. Unofficially, in 1976, the Society as we know it evolved out of the RIG structure, and the RIGs continued as a preliminary foundation for the Society. The critical mass of individuals who formed the RIGs, and what was to be known later as MNRS, became an affiliate of MAIN, and the MAIN staff provided administrative support to the Society's early conferences (McElmurry, 1981).

In 1977, the Society moved from an unofficial concept and organization to a more established structure through the affiliation with MAIN. An invitational meeting of 42 deans and directors from the Midwest was convened by Dean Elizabeth Grossman, Indiana University, at her home in Indianapolis. This 1977 meeting is considered to be the first gathering and first conference for MNRS. Benefits of an official organization dedicated to nursing research were discussed, and MNRS with its RIGs became a reality. Examples of RIGs included Health Seeking Behaviors, Historical Research Methodology, Qualitative Research Methodology, Theory Development, and Violence in the Family.

The second conference, held in Milwaukee, Wisconsin, and hosted by the University of Wisconsin-Milwaukee, was attended by 118 nurse researchers. Three research presentations were provided with small group discussions. The basic structure of the conferences was established at this time with schools (e.g., schools and colleges of nursing) hosting the conferences. By 1979, at the third conference, which was held in Detroit, Michigan, a convener, the precursor to MNRS's current RIG chair, organized each RIG. The RIGs were a mainstay of the organization and served to stimulate discussion and collaboration around a substantive research area. Individuals were invited to submit abstracts that were peer reviewed and selected for presentations. In 1980, MNRS was officially formed as an organization with the passage of the Society's By-Laws, adopting the official name, "Midwest Nursing Research Society," and holding the first election of officers. Dues were set at US\$35 per year, and Dr. Joyce Fitzpatrick became the first president. 
During its first decade of the 1980s, the Society grew rapidly and RIGs evolved into Research Sections. Roundtable discussions focused on research issues and methods in nursing. Research symposia and graduate student exchanges became a part of every annual conference, and the first MNRS award, the Distinguished Contribution to Nursing Research, was awarded in 1983 to Drs. Regina Lederman and Joanne Sabol Stevenson. Other firsts included the first Policy and Procedure Manual in 1983, the first issue of the MNRS Connection newsletter in 1984, and the first preconference in 1988, sponsored by the Qualitative Research Section. See Table 1 for other listings of the Society's notable firsts in its historical evolution.

In 1984, MNRS left MAIN, became incorporated as an independent organization, and hired an Administrative Manager. It returned to MAIN for management services from 1988 to 1995 . By the end of the first decade, MNRS had 1,000 members and became the largest nursing research organization in the United States (Glass, 2001, 2006).

MNRS entered its second decade in the 1990s, and conferences began to offer emerging researchers with opportunities for 30-min consultations with senior, and well-funded, MNRS nurse researchers. The "Honor a Researcher" program was initiated as a mechanism for honoring colleagues and fundraising. In addition, a research fund was created to award grants to support MNRS members. Donations were made through various funding levels, and the program was called the "Society of Scholars." As a result of these donations, the first MNRS research grant was awarded in 1994 with assistance from MAIN. A second grant was awarded in 1995 with assistance from Glaxo, Inc., and a third research grant was awarded in 1996 (Glass, 2001). Since that time, the number of grants awarded has varied, determined by funds available, as have the titles of the grants and the recipient criteria.

Nationally, nursing research was becoming valued and highly regarded. The Institute of Medicine published a report in 1983 recommending that nursing research be included in the mainstream of biomedical and behavioral science, and a 1984 National Institutes of Health (NIH) Task Force determined that nursing research activities were relevant to the NIH mission. These findings resulted in legislative action that established the National Center for Nursing Research in April 1986. With Public Law 103-43 in 1993, the center became an NIH Institute with a formal change in name to the National Institute of Nursing Research.

Also in the 1990s, MNRS reached out nationally to promote the value of nursing research through the Inter-Organizational Collaboration Committee, which consisted of the presidents of MNRS; the Western Society for Research in Nursing; the Southern Nursing Research Society; the Eastern Nursing Research Society; and the chair of the American Nurses Association Council 
Table I. MNRS Historical Evolution and Notable Firsts.

1977 - First Conference held at Dean Elizabeth Grossman's home

1978 - First Conference to include invitations to all Midwestern Schools and Colleges of Nursing

1980 - Affiliation began with the Midwest Alliance in Nursing (MAIN)

- Established By-Laws

- First President named: Dr. Joyce Fitzpatrick

1983 - First award presented: Distinguished Contribution to Research

- First Policy and Procedure Manual

1984 - First issue of the society newsletter: MNRS Connection

- First membership directory: Included 626 members

- MNRS is incorporated and leaves MAIN

1987 - First Leaders of Regional and National Research Groups meeting with MNRS participating

1988 - First Preconference Workshop sponsored by the Qualitative Research Section

- First Strategic Plan implemented

- Society members receive discounted subscription to Research in Nursing and Health

1989 - MNRS grows to the largest nursing research organization in the United States

1992 - MNRS senior researchers offer 30-min consultations to novice nurse researchers at the annual conference

- Honor a Researcher program initiated

- First Harriet H. Werley New Investigator Award presented

1993 - Society of Scholars created to establish research funding mechanism to support members' research

- First convening of the National Nursing Research Roundtable

1994 - First research grant awarded

1995 - Second research grant award added

1996 - First MNRS website was launched

- MNRS Nurse Researcher Listserv was established

- MNRS joins Research!America and Friends of the National Institute of Nursing Research

- MNRS publishes Guidelines for Scientific Integrity

- Third research grant award added

1999 - MNRS cosponsored the first State of the Science Nursing Research Conference in Washington, D.C.

2000 - Guidelines for Scientific Integrity translated to Spanish

- Conference abstracts entered into the Sigma Theta Tau International (Honor Society of Nursing) Index of Findings of the Registry of Nurse Researchers (now the Virginia Henderson Global Nursing e-Repository)

- First monograph published based on the 1997 Stress \& Coping Synthesis Conference 
Table I. (continued)

2001 - First dissertation research grant awarded

- First Hartford Institute/MNRS Geriatric Nursing Leadership Award is presented

- First Distinguished Service Award is presented

2002

- First Lifetime Achievement Award is presented

- MNRS Connection newsletter goes electronic

- Society adopts Western Journal of Nursing Research as the official journal; subscription now included with membership

2004 - Western Journal of Nursing Research awards "Best Faculty Paper" and "Best Student Paper" awards

- Leadership Workshop held for Research Section Chairs

2007 - MNRS Foundation is established

- First Foundation President named: Dr. Sally Lusk

2008 - First Connection Central at the conference

2012 - First time more than I,000 attendees at the annual conference

2014 - First MNRS Foundation raffle at the annual conference

2015 - First Employment Opportunities through paid advertisements and ability to connect on-site at the annual conference

2016 - Abstracts of Distinction are awarded to 3 paper, 3 poster, and 3 poster discussion presenters

Note. MNRS = Midwest Nursing Research Society; MAIN = Midwest Alliance in Nursing.

of Nurse Researchers. MNRS also joined "Research!America" and the "Friends of the National Institute of Nursing Research." In 1999, MNRS cosponsored the first national State of the Science Nursing Research Conference held in Washington, D.C.

In 2001, MNRS celebrated its 25th conference in Cleveland, Ohio, and the first dissertation award was given. The 2002 conference in Chicago, Illinois, saw attendance grow to more than 950 participants, and dues were now set annually at US\$150, which included a subscription to the Western Journal of Nursing Research. To encourage more students as emerging scholars, competitive undergraduate, graduate, and doctoral research posters became a major emphasis for the annual conferences (Glass, 2006). In 2006, the Society celebrated the 30th conference in Milwaukee, Wisconsin. The conference included 236 papers, 116 posters, 83 graduate student posters, and 28 undergraduate posters. At that time, there were 1,244 members and 27 Research Sections. The 35th conference was in Columbus, Ohio, in 2011, and the 40th conference returned to Milwaukee, Wisconsin, in 2016. In 2012, a milestone was reached as more than 1,000 people registered for the conference held in Dearborn, Michigan. 
A pivotal year for MNRS was 2007 as the MNRS Board of Directors charged Dr. Sally Lusk with leading a committee to develop plans for a foundation as a charitable organization within MNRS. One year later, in 2008, the plans for the MNRS Foundation were presented to and approved by the Board, establishing MNRS as the only regional nursing society with a foundation whose mission would be to advance and support research, research utilization, and research careers in accordance with the values of MNRS. These groundbreaking efforts led directly to the MNRS Foundation receiving Internal Revenue Service approval as a 501(c3) charitable organization. Soon after the Foundation's official designation as a charitable organization, it initiated a joint grant with the National League for Nursing and continued to contribute to funding the joint grants with the American Nurses Foundation and Sigma Theta Tau International, the Honor Society of Nursing. Special designated funding mechanisms were developed and promulgated, including the Founders' Circle, Anniversary Circle, Legacy Gifts, and Pillars of Excellence.

From the first meeting held in 1977 at Dean Grossman's home, to the second conference in 1978, open to all Midwestern schools, with 118 attendees and three research presentations, MNRS has grown in 2016 to offer 322 competitive research and evidence-based practice presentations and 238 student poster presentations, with 1,100 attendees. Now, as MNRS enters its fourth decade, it is important to examine the driving forces that created MNRS, acknowledge the challenges and opportunities that produced such a strong organization for nursing research, and provide direction for the future.

\section{Challenges and Opportunities for MNRS}

As with any new professional organization, MNRS faced challenges in key areas of membership, finances, and organizational structure. But it is important to note that throughout its history, through strong leadership and dedicated members, MNRS responded to the challenges and seized opportunities to advance nursing research in the Midwest region. The Society, through strategic planning and member communication, has continuously sought to meet the needs of members. In the early years, MNRS focused on the development of new members (many of whom had new doctoral degrees) by offering opportunities to present research, collaborate with other investigators to build nursing science, and gain research skills through preconference methodological and focused area sessions. MNRS met the needs for schools and members to enhance their research reputation through podium and poster presentations and participation in leadership roles at the RIG and Board of Director levels. It also offered awards (such as the Distinguished Contribution to Research, Early Investigator, and Dissertation awards) and small research grants. Table 
Table 2. MNRS Historical Information Access.

\begin{tabular}{|c|c|}
\hline MNRS Website Links & MNRS Archived Information \\
\hline $\begin{array}{l}\text { Founding Members } \\
\text { https://www.mnrs.org/mnrs-founding- } \\
\text { members } \\
\text { Past Presidents } \\
\text { https://www.mnrs.org/about-mnrs/history/ } \\
\text { past-presidents/mnrs-past-presidents } \\
\text { Past MNRS Grant Recipients (includes } \\
\text { MNRS Dissertation Research Grant } \\
\text { Recipients, MNRS Seed Grant Recipients, } \\
\text { MNRS/STTI Grant Recipients, MNRS/ANF } \\
\text { Grant Recipients, and MNRS Mentorship } \\
\text { Grant Recipients) } \\
\text { https://www.mnrs.org/past-grant- } \\
\text { recipients\#MNRS Dissertation Research } \\
\text { Grant Recipient - Archive } \\
\text { Past MNRS Award Recipients (includes } \\
\text { MNRS/John A. Hartford Foundation } \\
\text { Award Recipients, Distinguished Service } \\
\text { Award Recipients, Lifetime Achievement } \\
\text { Award Recipients, Distinguished } \\
\text { Contribution to Research Award } \\
\text { Recipients, Harriet H. Werley New } \\
\text { Investigator Award Recipients, and Senior } \\
\text { Scientist Award Recipients) } \\
\text { https://www.mnrs.org/past-award-recipients }\end{array}$ & $\begin{array}{l}\text { The MNRS archived materials are } \\
\text { located at University of Illinois } \\
\text { at Chicago, Library of the Health } \\
\text { Sciences, Special Collections, } \\
\text { I } 750 \text { West Polk Street, Room } \\
\text { 320, Chicago, IL 606I2. } \\
\text { For additional details, see http:// } \\
\text { www.uic.edu/depts/lib/specialcoll/ } \\
\text { services/rjd/findingaids/MNRSf. } \\
\text { html }\end{array}$ \\
\hline
\end{tabular}

Note. MNRS = Midwest Nursing Research Society; STTI = Sigma Theta Tau International; ANF $=$ American Nurses Foundation.

2 provides electronic links for accessing historical information about awardees, founding members, past presidents, and other archived information.

The commitment to advancing nursing research through multilevel organizational support grew the membership through much of the 1990s. Schools of nursing and individual members strongly supported the organization through annual membership fees and conference registration fees. There was a strong commitment to the organization among member schools and nurse faculty. Senior and funded researchers were accompanied by their research team members to conferences as school prestige and faculty promotion and tenure were often linked to MNRS activities. During these years, some schools made MNRS a part of the doctoral program curriculum requiring attendance at MNRS as part of professional socialization. The Harriet $\mathrm{H}$. 
Werley New Investigator Award was established during this time frame (1992) and added to the Society's ability to advance nursing research by recognizing stellar contributions from its new investigators. This highly competitive award, bestowed annually upon an MNRS member who has completed his or her doctorate within the past 7 years, is highly predictive of future success as a nurse scientist.

One of the highlights of MNRS has always been the annual conference. Members and schools provided intense levels of support in the early years, particularly conference host schools, because the first decade occurred prior to the advent of technological and computer resources that are commonplace today. Calls for abstracts, abstract submission, program planning, and notification were all done manually and via postal mail. Meeting support for the details of hotel selection and booking, and details of the on-site conference were ably managed by the MAIN services initially and later by contracted management associations. Even today, host schools and the MNRS Board continue to have many demands on time and resources, a component that is similar in other membership organizations with a heavy reliance on volunteer participation from elected officers and members.

MNRS expanded its membership recruitment in several ways over the years as resources became less available for many investigators and schools. One of the first efforts to meet this challenge was a large program developed to solicit students' research and recognize the best posters with awards at each educational level. This program resulted in ensuring that students were exposed to a scientific meeting early in their education while also making them aware of MNRS. Thus, the benefits included the potential of engaging students in a research-focused career and recruiting them as long-term MNRS members. This expansion of membership also garnered increased interest of the schools and faculties in participating with their students in the annual meeting. Early engagement of students, opportunities for leadership in RIG activities, and an informed and invested membership contributed to the ongoing success of the organization as students presented research, participated in and volunteered for RIG planning and organization and, as their careers unfolded, ran for and held offices and served on the Board of Directors. Thus, the inclusiveness of the structure and organizational activities supported the growth and legacy of the organization, a trend that continues to this day.

With the growth in membership and subsequent expansion of organizational structures like the RIGs, the Society experienced challenges in managing the multilayers of the organization. For the RIGs, as the membership and its substantive research areas grew into multiple RIGs, known as Research Sections at the time, the Society grappled with the logistical challenges of managing and supporting the number of Research Sections, low participation 
in some Research Sections, and overlap between the priorities of the Sections. In 2012, the MNRS Board and RIG leaders took on the difficult task of reorganizing the RIGs to a more effective, member-friendly structure. Outgrowths of the rebuilding of the RIGs included the formation of new communication venues for RIG members (e.g., LinkedIn) and the recognition of the need, and opportunity, to intensify efforts toward building leadership capacity for nursing research. Establishing the Emerging Scholars Network in 2011 and granting voting rights for representatives of the Emerging Scholars Network to all MNRS committees (excluding the Grants and Awards committees) in 2014 are examples of how MNRS and its members responded. Furthermore, and in part because of the success of the Emerging Scholars Network, over the past 2 years, MNRS has launched efforts to investigate member interest in a Mid-Career Scholars Network and a Senior Scholars Network.

Another challenge for the Society has been to stay relevant as the discipline of nursing itself evolves. MNRS Board members and other senior leaders recognized an increased focus on clinical nursing research and evidence-based practice within the clinical practice setting as the Doctor of Nursing Practice (DNP) educational programs gained momentum and wide acceptance. As the numbers of faculty with DNPs expand, MNRS is actively seeking to meet the needs of both PhD and DNP educated members with an interest in clinical and translational research and collaboration across settings and educational degrees.

As the economic downturn in national research funding took hold over the past few decades, MNRS recognized the critical need to support nursing research in the Midwest and responded by increasing the number of small research grants awarded. Although still not offering as many grants and as much funding as desired, MNRS established itself as a good source for dissertation and seed grant funding, especially over the past 10 years when the number of MNRS grants and the dollar amounts associated with the grants expanded. Further, because the grant review and selection process is rigorous, using criteria and a process modeled on the NIH review procedures, receipt of an MNRS grant is widely recognized as a significant accomplishment.

Because of the need to raise more funds to offer more grants, as previously mentioned, in 2007, the MNRS Board of Directors approved the creation of the MNRS Foundation. The benefits of the Foundation are as follows: (a) to give a clear message of separateness from day-to-day operations of the Society, (b) to give more confidence to donors that the funds will be used as intended, (c) to make it more acceptable to promote giving through dues check-off or special solicitations, (d) to have a separate Board of Trustees whose purpose would be the recruitment of funds, and (e) to provide the opportunity to involve corporate representatives on its Board to add expertise in raising 
funds. Although this effort had begun during an economic downturn, the MNRS Foundation investment fund currently exceeds US $\$ 300,000$ raised primarily from MNRS members. A portion of the interest from this investment fund has been used to award a grant each year. These and other funds raised by the Foundation from members and external donors are combined with funds allocated from the MNRS annual budget. The combined funds allowed MNRS to award about US $\$ 45,000$ in grant funding this past year.

Efforts by the Foundation to recruit funds for research have taken a variety of forms. From the outset, the Board of Trustees assumed the responsibility for holding fundraising activities at the annual conference that included galas, silent auctions, and raffles. Brochures were developed to promote fundraising from several sources, including MNRS members, the general public, institutions and corporations (Pillars of Excellence program), and legacy gifts. In addition, two sets of videos were created. The first featured interviews with five members who had received MNRS grants to describe their research and to share the impact of the receipt of the funds. The target audience for these videos was MNRS members with viewings at an annual conference and with availability on the website. The second set, developed to be used with lay audiences, again featured MNRS grant recipients, but the interviews focused on the practical outcomes and clinical implications of their research. The purpose was to educate the public regarding the contributions of nursing research, and thereby solicit funds. The MNRS website has a link to these videos on YouTube (see MNRS, n.d., for access to the videos). Several schools of nursing reported using both sets of videos for classes to introduce students to the many facets of nursing research. In part because of the strong commitment and long history of engaging students and young scientists in MNRS, a new approach to solicit funds, spearheaded by members of the Emerging Scholars Network and launched in August 2016, is the utilization of GoFundMe, a novel Internet-based "crowdfunding" platform (Lach \& Brown, 2017). The GoFundMe platform allows MNRS members and nonmembers to create and share the platform with others through social networks and email. In addition, the MNRS Foundation is listed as one of the charities to which AmazonSmile will award funds, based on purchases made by supporters.

\section{Directions for the Future of MNRS}

In the future, as in the past, MNRS needs to continue the commitment to the member experience through strategic planning, member communication and service, anticipating and recognizing changes in nursing science and futuristic thinking, and maintaining its many well-recognized strengths. The strengths of the annual conferences include the high-quality papers and presentations, 
the prestige of presenting at the meeting, facilitated networking opportunities among peers, access to nursing leaders, poster competitions, and the combination of continuing education offerings and scientific presentations.

Pragmatic recommendations include the importance of good member services to ensure MNRS will continue to grow. These services must be responsive, relevant, and reasonably priced, as well as provide up-to-date technology and facilitate networking between meetings.

With the need for and a dearth of funds for pilot studies, it is imperative for MNRS to expand the numbers and amounts of research grants. Progress can be made in this arena in the short term by partnering with other organizations in offering joint grants. More knowledge about the impact our research grants have on science and the careers of the awardees would also be beneficial. Now that the MNRS Foundation Founders' Circle has achieved an interim goal, the interest earned on the money in that fund is beginning to provide support for grants. There is a need to continue growing the amount in the endowment fund, and this will require not just contributions from MNRS members but recruitment of donations from external sources. To encourage donations, the Foundation Board of Trustees (charged with raising funds) will benefit from expert consultation and financial support for fundraising. There is also an opportunity to seek additional external funds to support conference activities from entities not currently represented at the conferences. This would allow reallocation of Society resources so that more funds can be released to support research grants and support fundraising activities.

Over the years, MNRS has been supported by capable, committed leaders. This strong leadership is expected to continue as MNRS is recognized as a premier research organization, with a rich history and a well-developed, stable organizational structure positioned for growth in financial and member resources. The future is bright!

The visionaries who spawned MNRS fostered the development of nursing research, thus creating opportunities for nurse researchers to develop programs of research, to access funding, and to find a voice among nursing colleagues as a preamble to contributing to the practice of nursing through research and interdisciplinary scientific contributions. As nursing science and research has developed over the last 40 years, MNRS has been instrumental in contributing to a quality environment for that growth.

\section{Authors' Note}

Required for Dr. Karen M. O'Connell: The views and opinions expressed in this article are those of the authors and do not reflect official policy of the United States Air Force, the Department of Defense, or the United States Government. 


\section{Acknowledgments}

Many Midwest Nursing Research Society (MNRS) members graciously provided assistance to the authors as the manuscript was developed. The authors would especially like to thank Dr. Brigid Lusk, MNRS Archivist; Emerging Scholars Network leaders; and Samantha Adams, MNRS Director of Membership and Special Projects. They also acknowledge the MNRS Historical Task Force Members and the 2016 Program Planning Committee Members who developed and supported the 2016 MNRS Conference Session, The Midwest Nursing Research Society: Learning From Our Past to Excel for the Future, as this article is an outgrowth of the session. They are indebted to the session presenters (authors: Christine A. Wynd, Joyce J. Fitzpatrick, Nancy Bergstrom, and Sally Lechlitner Lusk) including Dr. Susan Rawl, who served as moderator for the conference session.

\section{Declaration of Conflicting Interests}

The author(s) declared no potential conflicts of interest with respect to the research, authorship, and/or publication of this article.

\section{Funding}

The author(s) received no financial support for the research, authorship, and/or publication of this article.

\section{References}

Glass, L. K. (2001). Celebrating 25 years, MNRS historical highlights [Monograph]. Chicago, IL: Midwest Nursing Research Society.

Glass, L. K. (2006). MNRS 30 year history update. Unpublished manuscript.

Institute of Medicine. (1983). Nursing and nursing education: Public policies and private actions [OpenBook version]. Retrieved from http://www.nap.edu/openbook.php?isbn $=0309033462$

Lach, H. W., \& Brown, R. (2017). Midwest Nursing Research Society news: A team approach to fundraising. Western Journal of Nursing Research, 39, 204-207. doi:10.1177/0193945916680662

McElmurry, B. J. (1981, May-June). Research in the Midwest. Sigma Theta Tau Reflections, pp. 8-9.

McElmurry, B. J., \& Minckley, B. B. (1986). Regional research networking: A stimulus to research collaboration and research productivity. Journal of Professional Nursing, 2, 208-216. doi:10.1016/S8755-7223(86)80042-4

Midwest Nursing Research Society (Producer). (n.d.). MNRS foundation: Grant recipient videos. Retrieved from http://www.mnrs.org/foundation/grant-recipient-videos

Minckley, B. B. (1980). Nursing research and regionalization in the Midwest. Nursing Research, 29, 193-198. doi:10.1097/00006199-198005000-00012 